\title{
Twenty-three years of single-stage end-to-side anastomosis repair of interrupted aortic arches
}

\author{
Aisyah Hussein, BMedSci, ${ }^{\mathrm{a}}$ Ajay J. Iyengar, MBBS, BMedSci, ${ }^{\mathrm{a}}$ Bryn Jones, FRACP, ${ }^{\mathrm{b}}$ \\ Susan M. Donath, MA, ${ }^{\mathrm{c}}$ Igor E. Konstantinov, MD, PhD, ${ }^{\mathrm{a}}$ Leeanne E. Grigg, MBBS, FRACP, ${ }^{\mathrm{d}}$ \\ Gavin Wheaton, MBBS, FRACP, FCSANZ, ${ }^{\mathrm{e}}$ Andrew Bullock, MBBS, FRACP, \\ Christian P. Brizard, MD, a and Yves d'Udekem, MD, $\mathrm{PhD}^{\mathrm{a}}$
}

Objective: This study defined long-term results of a policy of single-stage repair of interrupted aortic arch with end-to-side anastomosis.

Methods: Records of 112 consecutive patients undergoing interrupted aortic arch repair between 1985 and 2007 were reviewed. Single-stage repair was performed in 95 patients, with 90 having end-to-side repair.

Results: There were 11 in-hospital deaths (10\%). Twelve patients needed arch reintervention during the same hospital stay: 7 for residual arch obstruction and 5 for left main bronchus obstruction. Nine patients were unavailable for follow-up. After a mean of $10 \pm 7$ years, 6 late deaths occurred, for 18 -year survival of $92 \%(95 \%$ confidence interval [CI], 84\%-97\%). Patients with end-to-side anastomoses had better 18 -year survival $(97 \%, 95 \%$ CI, $87 \%-99 \%$, vs $74 \%, 95 \%$ CI, $44 \%-89 \%, P<.01)$. After discharge, 19 patients underwent further aortic arch intervention. The only factors predictive of late arch reintervention were technique other than end-to-side $(P<$ $.001)$ and reoperation for left outflow tract obstruction. Freedom from arch reintervention after end-to-side repair was $78 \%$ at 18 years $(95 \% \mathrm{CI}, 59 \%-89 \%)$ ). Another 16 patients had significant residual obstruction. The 18 -year freedom from hypertension was $88 \%(95 \%$ CI, $72 \%-95 \%)$.

Conclusions: Single-stage repair with end-to-side anastomosis seems the best approach for most neonates with interrupted aortic arch, because it provides relief of the arch obstruction with low early mortality. After 2 decades of experience with this approach, incidence of late hypertension seems minimal. The need for further arch reintervention warrants close follow-up of these patients. (J Thorac Cardiovasc Surg 2010;139:942-9)

Earn CME credits at

http://cme.ctsnetjournals.org

The outcomes of patients undergoing single-stage repair of interrupted aortic arch without graft interposition have been well delineated only for the first years after repair. ${ }^{1-11}$ Little is known yet regarding the late outcomes of these patients in the second decade after surgery, especially in terms

From the Departments of Cardiac Surgery ${ }^{\mathrm{a}}$ and Cardiology ${ }^{\mathrm{b}}$ and the Clinical Epidemiology and Biostatistical Unit, ${ }^{\mathrm{c}}$ Royal Children's Hospital, The University of Melbourne Department of Paediatrics and the Murdoch Children's Research Institute, Melbourne, Australia; the Department of Cardiology, ${ }^{\mathrm{d}}$ Royal Melbourne Hospital, Melbourne, Australia; the Department of Cardiology, ${ }^{\mathrm{e}}$ Women's and Children's Hospital, Adelaide, Australia; and the Department of Cardiology, ${ }^{\mathrm{f}}$ Princess Margaret Hospital for Children, Perth, Australia.

Disclosures: None.

Received for publication May 1, 2009; revisions received Aug 16, 2009; accepted for publication Sept 6, 2009.

Address for reprints: Yves d'Udekem, MD, PhD, Department of cardiac Surgery, Royal Children's Hospital, Flemington Rd, Parkville, Melbourne 3052, Victoria, Australia (E-mail: yves.dudekem@rch.org.au).

0022-5223/\$36.00

Crown Copyright (C) 2010 Published by Elsevier Inc. on behalf of The American Association for Thoracic Surgery

doi:10.1016/j.jtcvs.2009.09.069 of recurrence of arch obstruction and prevalence of hypertension. During the last 2 decades, our team has consistently adopted a policy of single-stage repair of interrupted aortic arch with end-to-side anastomosis. We review here our experience with this approach.

\section{MATERIALS AND METHODS}

The study was approved by the hospital's Ethics and Human Research Committee. The end-to-side repair of interrupted aortic arch was introduced in 1985 in the Royal Children's Hospital in Melbourne, Australia. The records of all patients who had undergone an interrupted aortic arch repair from January 1985 to June 2007 were reviewed.

\section{Patients}

There were 112 patients, comprising 100 operated on as neonates (age, $<30$ days) and 12 as infants. The characteristics of the patients are given in Table 1.

Shunting occurred at the level of the great vessels through an aortopulmonary window in 4 patients and at the ventricular level in 91 patients (13 truncus, 7 double-outlet right ventricle, 10 transposition of the great arteries, 2 atrioventricular septal defect, and 59 isolated ventricular septal defects [VSDs]). The remaining 16 patients had functionally univentricular heart. A single patient with interruption type A with Williams syndrome and supravalvular aortic stenosis had no identified shunting.

Thirty-five of the 37 patients found to have 22q11 deletion had a type B interruption. Three patients (1 each) had Charge, Kabuki, and Schprintzen syndromes. Before surgery, 33 patients $(29 \%)$ required the combination of mechanical ventilation, prostaglandin infusion, and inotropic support. 


\section{Abbreviations and Acronyms \\ $\mathrm{CI} \quad=$ confidence interval \\ LVOT $=$ left ventricular outflow tract \\ $\mathrm{VSD}=$ ventricular septal defect}

\section{Surgical Procedures}

Ninety-five patients $(85 \%)$ underwent end-to-side repair with cardiopulmonary bypass by sternotomy; the remaining $17(15 \%)$ underwent some other procedure. The technique of end-to-side repair was consistent. Through the median sternotomy, the head vessels and the descending aorta were extensively dissected. With cardiopulmonary bypass, during cooling, the first 3 pairs of intercostal arteries were cauterized and divided. Before 2000, all patients underwent arch repair during deep hypothermic circulatory arrest. Since 2000 , all patients have undergone operation with selective cerebral perfusion. For selective cerebral perfusion, a straight, wire-reinforced cannula is inserted in the ascending aorta, just below the emergence of the innominate artery. After cooling to $25^{\circ} \mathrm{C}$, the aorta is crossclamped and cardioplegia administered in the aortic root. The arterial cannula is advanced in the innominate artery and snared in position. The flow is reduced to $10 \%$ to $25 \%$ of the estimated full flow of the patient, according to the continuous monitoring of the right radial arterial reading. The remaining head vessels are then snared to proceed with the repair. All ductal tissue is extensively resected. An incision is made in the posterior aspect of the ascending aorta and the transverse arch, opposite the emergence of the innominate artery (Figure 1). After completion of the repair and deairing of the arch, the cannula is repositioned in the ascending aorta and full cardiopulmonary bypass reestablished.

Of the 17 patients who did not undergo end-to-side repair, 10 underwent operation by thoracotomy between 1985 and 1997 . Three of these underwent left subclavian flap repair, 4 underwent end-to-end anastomosis, 1 underwent end-to-side repair, and 2 underwent 8-mm GORE-TEX graft interposition (W. L. Gore \& Associates, Inc, Flagstaff, Ariz). The remaining 7 patients underwent operation by sternotomy with cardiopulmonary bypass. Four patients underwent concomitant Damus procedures; in these patients, the 2 segments of aorta were approximated and the concavity of the arch was reconstructed with patches of autologous pericardium ${ }^{3}$ or homograft pericardium. ${ }^{1}$ One patient had a patch added to an end-to-side repair, 1 had a 10$\mathrm{mm}$ aortic homograft interposition, and 1 had a left subclavian flap repair. When not used in a flap repair, the left subclavian artery was left intact.

Single-stage repair was performed in 97 patients $(87 \%)$, with 90 of these undergoing end-to-side repair by sternotomy. The associated procedures are listed in Table 1.

\section{Subaortic Stenosis}

Thirty-five patients had suspected restrictive left ventricular outflow tract (LVOT). Relief of the restriction was determined by inspection of the LVOT. Twenty-two patients with LVOT restriction underwent no intervention at this level. One patient with 2 morphologic ventricles and 3 with single-ventricle morphology underwent Damus procedures. One patient underwent an arterial switch procedure, and the remaining 8 underwent resection of the obstructed LVOT (7 resections of the conal septum and 1 of a fibrous shelf).

\section{Outcomes}

In-hospital mortality was defined as death before discharge from the hospital or within 30 days afterward. Late arch obstruction was noted for patients who underwent arch reintervention, were found to have a gradient greater than $20 \mathrm{~mm} \mathrm{Hg}$ between the arm and leg, or had an echocardiographically identified peak gradient greater than $25 \mathrm{~mm} \mathrm{Hg}$ in the descending aorta. Patients were considered to be hypertensive when specifically de- scribed as hypertensive by the referring cardiologist, when systolic blood pressure was greater than $133 \mathrm{~mm} \mathrm{Hg}$, or when diastolic blood pressure was greater than $78 \mathrm{~mm} \mathrm{Hg} .^{12}$

\section{Statistical Analysis}

Data were reported as mean $\pm \mathrm{SD}$ or as median with interquartile range. All tests were 2-tailed. All preoperative and perioperative variables were tested by univariate analysis for prediction of in-hospital mortality, and significant factors were entered into a stepwise logistic regression analysis. The list of analyzed parameters is given in Appendix 1. Kaplan-Meier survival analysis and hazard function analysis were performed for time-related events (late survival, arch reintervention, and recurrent arch obstruction). Risk factors for time-related events were tested by the Cox proportional hazards method. All data were analyzed with Stata version 10.0 (StataCorp LP, College Station, Tex).

\section{RESULTS}

\section{In-Hospital Mortality}

There were 11 early deaths, for an in-hospital mortality of $10 \%$ : 6 of 38 patients with type A interruption (16\%) and 5 of 72 with type $\mathrm{B}(7 \%, P=.13)$. The causes of death were low-output syndrome $(\mathrm{n}=6)$, pulmonary hypertension $(\mathrm{n}=3)$, pneumonia $(\mathrm{n}=1)$, and Staphylococcus aureus endocarditis $(n=1)$. Two of the patients who died of low-output syndrome had residual arch obstruction diagnosed. The postoperative course of 1 patient who died of pulmonary hypertension was complicated by compression of the left bronchus. Seven of the 90 patients who had undergone a onestage end-to-side repair $(8 \%)$ and 4 of the 22 operated with a different technique (18\%) died $(P=.15)$. Two of the 13 patients born with truncus arteriosus and 3 of the 16 with a functionally univentricular heart also died. By univariate analysis, only lack of VSD closure predicted mortality $(P<.05)$.

\section{Postoperative Complications}

Ventilation time, intensive care unit stay, and hospital stay were available for 81 patients. The median ventilation time was 4 days ( $2-7$ days, end-to-side repair 4 days [2-7 days] and other 4 days $[2-5$ days], $P=.19$ ), the median intensive care unit stay was 5 days (4-11 days, end-to-side repair 5 days [4-10 days] and other 8 days [3-20 days], $P=.14$ ), and the median hospital stay was 5 days (11-30 days, endto-side repair 14 days [10-28 days] and other 29 days [14-35 days], $P=.23$ ).

Four of the 95 patients who underwent end-to-side repair and 3 of the 17 who underwent another procedure needed an early arch reintervention after a median of 29 days (9-43 days). Three of them underwent balloon dilatation. Two patients with previous truncus arteriosus repair underwent patch augmentation of the repair. The 2 remaining patients had univentricular hearts and needed reoperative correction of the Damus procedure with patch repair of the arch. One of them subsequently died.

Left main bronchus compression was identified after repair in 7 patients (6 end-to-side repairs, 3 associated with truncus arteriosus). Five of these patients required 
TABLE 1. Patient characteristics

\begin{tabular}{|c|c|c|c|c|}
\hline Variables & Total $(n=112)$ & End-to-side (n = 95) & Other $(n=17)$ & $P$ value \\
\hline Sex (male/female ratio) & $59: 53$ & $48: 47$ & $11: 6$ & \\
\hline \multicolumn{5}{|l|}{ Type of interruption (no.) } \\
\hline Type A & $38(34 \%)$ & $26(27 \%)$ & $12(71 \%)$ & $<.001$ \\
\hline Type B & $72(64 \%)$ & $67(71 \%)$ & $5(29 \%)$ & $<.001$ \\
\hline Type C & $2(2 \%)$ & $2(2 \%)$ & $0(0 \%)$ & .546 \\
\hline \multicolumn{5}{|l|}{ Associated cardiac anomalies (no.) } \\
\hline Ventricular septal defect & $87(78 \%)$ & $76(80 \%)$ & $11(65 \%)$ & .163 \\
\hline Univentricular heart & $16(14 \%)$ & $8(8 \%)$ & $8(47 \%)$ & $<.001$ \\
\hline Double-inlet left ventricle & $6(5 \%)$ & $5(5 \%)$ & $1(6 \%)$ & .917 \\
\hline Truncus arteriosus & $13(12 \%)$ & $12(13 \%)$ & $1(6 \%)$ & .424 \\
\hline Transposition of great arteries & $11(10 \%)$ & $7(7 \%)$ & $4(24 \%)$ & $<.05$ \\
\hline Double-outlet right ventricle & $7(6 \%)$ & $4(4 \%)$ & $3(18 \%)$ & $<.05$ \\
\hline Aortopulmonary window & $4(4 \%)$ & $4(4 \%)$ & $0(0 \%)$ & .389 \\
\hline Subaortic stenosis & $35(31 \%)$ & $29(31 \%)$ & $6(35 \%)$ & .696 \\
\hline Bicuspid aortic valve & $24(21 \%)$ & $24(25 \%)$ & $0(0 \%)$ & $<.05$ \\
\hline Aberrant right subclavian artery & $22(20 \%)$ & $21(22 \%)$ & $1(6 \%)$ & .121 \\
\hline Noncardiac anomaly (22q11 deletion, no.) & $37(33 \%)$ & $36(38 \%)$ & $1(6 \%)$ & $<.05$ \\
\hline \multicolumn{5}{|l|}{ Clinical symptoms (no.) } \\
\hline Renal failure & $50(45 \%)$ & $41(43 \%)$ & $9(53 \%)$ & .940 \\
\hline Necrotizing enterocolitis & $5(5 \%)$ & $5(5 \%)$ & $0(0 \%)$ & \\
\hline \multicolumn{5}{|l|}{ Preoperative management (no.) } \\
\hline Prostaglandin infusion & $84(75 \%)$ & $73(58 \%)$ & $11(65 \%)$ & .344 \\
\hline Mechanical ventilation & $54(48 \%)$ & $50(53 \%)$ & $4(24 \%)$ & .171 \\
\hline Inotropic support & $44(39 \%)$ & $40(42 \%)$ & $4(24 \%)$ & .575 \\
\hline Age at operation (d) & & & & .911 \\
\hline Median & 6 & 6 & 6 & \\
\hline Interquartile range & $4-11$ & $4-12$ & $3-11$ & \\
\hline \multicolumn{5}{|l|}{ Associated procedures (no.) } \\
\hline Ventricular septal defect closure & $74(66 \%)$ & $71(75 \%)$ & $3(18 \%)$ & $<.001$ \\
\hline Left ventricular outflow tract obstruction relief & $8(7 \%)$ & $7(7 \%)$ & $1(6 \%)$ & .827 \\
\hline Damus shunt & $11(10 \%)$ & $8(8 \%)$ & $3(18 \%)$ & .239 \\
\hline Pulmonary artery banding & $12(11 \%)$ & $6(6 \%)$ & $6(35 \%)$ & $<.001$ \\
\hline Operation type (1-stage/2-stage ratio) & $97: 15$ & $90: 5$ & $7: 10$ & $<.001$ \\
\hline \multicolumn{5}{|l|}{ Cardiopulmonary bypass } \\
\hline Used (no.) & $101(90 \%)$ & $93(98 \%)$ & $8(47 \%)$ & $<.001$ \\
\hline Mean duration (min, mean $\pm \mathrm{SD}$ ) & $138 \pm 67$ & $136 \pm 67$ & $166 \pm 69$ & .228 \\
\hline \multicolumn{5}{|l|}{ Circulatory arrest } \\
\hline Used (no.) & $86(77 \%)$ & $78(82 \%)$ & $6(35 \%)$ & .291 \\
\hline Mean duration (min, mean $\pm \mathrm{SD}$ ) & $37 \pm 17$ & $37 \pm 18$ & $36 \pm 13$ & .921 \\
\hline Minimum temperature $\left({ }^{\circ} \mathrm{C}\right.$, mean $\left.\pm \mathrm{SD}\right)$ & $18 \pm 5$ & $18 \pm 4$ & $19 \pm 9$ & .786 \\
\hline
\end{tabular}

reintervention: two interposition of an 8-mm GORE-TEX conduit, 1 required aortic homograft interposition, and 2 required aortopexy. No preoperative or perioperative variables were significantly associated with a risk of postoperative bronchial obstruction. Nine patients needed another reoperation to perform the following 10 cardiac procedures: adjustment of pulmonary artery banding $(n=3)$, relief of residual LVOT obstruction $(n=2)$, VSD closure $(n=1)$, atrioventricular septal defect repair $(n=1)$, arterial switch procedure and right modified Blalock-Taussig shunt $(\mathrm{n}=1)$, Norwood procedure $(\mathrm{n}=1)$, and cavopulmonary anastomosis $(\mathrm{n}=1)$. Additional complications encountered were diaphragm paralysis necessitating plication $(\mathrm{n}=3)$ and complete heart block necessitating pacemaker implantation after VSD closure $(n=2)$. None of the patients who required enlargement of the LVOT required pacemaker implantation.

\section{Late Outcomes}

Survival. Eighty-two of the 101 immediate survivors left the hospital with an end-to-side repair and 19 with another procedure. Nine of these 101 hospital survivors were unavailable for follow-up (6 end-to-side repairs). Concurrent follow-up (2004-2008) was 79\% (80/101 patients). Mean follow-up was $10 \pm 7$ years. Six patients died within 5 years of the arch repair (3 end-to-side repairs). Causes of death were sudden cardiac death $(n=2)$, reoperative surgery for 


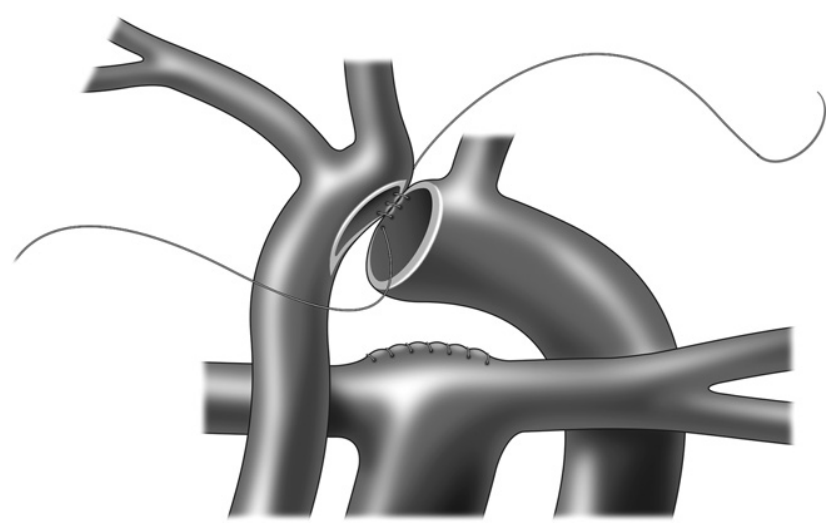

FIGURE 1. End-to-side repair.

associated cardiac lesions $(n=2)$, respiratory failure with left main bronchus compression $(\mathrm{n}=1)$, and postvaccination anaphylactic shock $(n=1)$. Hospital survivors of interrupted aortic arch repair achieved an 18-year survival of $92 \%$ (95\% confidence interval [CI], 84\%-97\%). Significant variables affecting late survival are listed in Appendix 2. There were no independent predictors of late mortality. (Figure 2). The 18-year survivals were 97\% (95\% CI, $87 \%-99 \%$ ) after end-to-side repair and $74 \%$ after the other procedures $(95 \% \mathrm{CI}, 44 \%-89 \% ; P<.05)$.

Reintervention not related to the aortic arch. Three of the 8 patients who underwent resection of LVOT obstruction and 3 of the 22 with suspected obstruction who did not undergo any resection during their first hospital stay needed later resection of the LVOT obstruction after a mean of 4 \pm 4 years. In a single patient among those who had no initial resection of the LVOT, the intervention consisted of a RossKonno procedure. An additional 22 patients underwent the following 28 procedures: replacement of right ventricle-pulmonary artery conduit $(\mathrm{n}=9)$, bidirectional cavopulmonary shunting $(n=8)$, Fontan operation $(n=6)$, pacemaker insertion $(\mathrm{n}=4)$, and arterial switch procedure $(\mathrm{n}=1)$.

Arch reintervention. Nineteen patients needed arch reintervention after a mean of $8 \pm 6$ years. Eleven of these

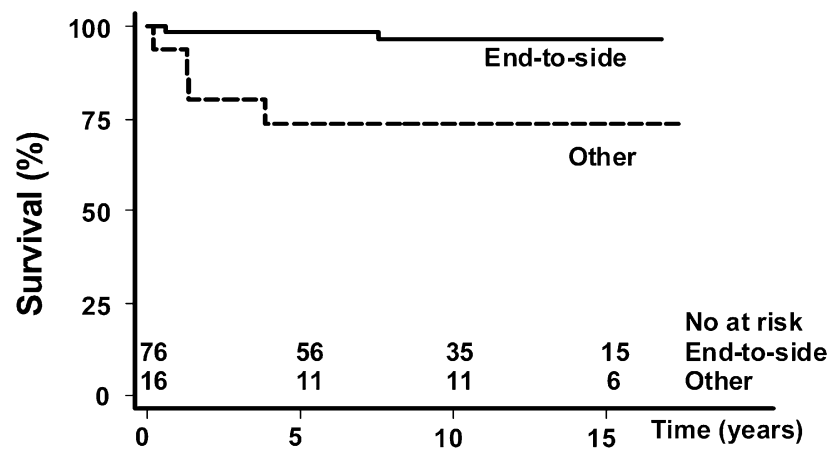

FIGURE 2. Kaplan-Meier survival graph for 92 of 101 hospital survivors of repair ( 9 patients unavailable for follow-up). patients were among the 78 discharged from the hospital with an end-to-side repair. Eleven patients underwent balloon dilatation of the arch, and 1 underwent balloon dilatation and stenting. Three of these procedures failed, and the patients needed subsequent surgery. Seven patients were sent directly to surgery. The 18 -year freedom from aortic arch reintervention was $69 \%$ (95\% CI, 52\%-81\%). Independent predictors of arch reintervention were undergoing a procedure other than an end-to-side repair $(P<.001)$ and undergoing reoperation for LVOT obstruction $(P<$ $.05)$. The 18-year freedom from arch reintervention after end-to-side repair was 78\% (95\% CI, 59\%-89\%; Figure 3 and Appendix 2).

Arch obstruction. A total of 33 patients were considered to have recurrent arch obstruction. The 18-year freedom from aortic arch obstruction was $46 \%(95 \%$ CI, 31\%-61\%). Eighteen years after end-to-side repair, the freedom from arch obstruction was $51 \%$ (95\% CI, 34\%-66\%). The multivariate Cox regression analysis revealed that patients with an aberrant right subclavian artery, those operated on with a procedure other than end-to-side anastomosis, and those needing further relief of LVOT obstruction had higher chances of recurrent arch obstruction $(P<.05$; Figure 4 and Appendix 2).

Late hypertension. Only 5 patients were found to be hypertensive at last follow-up. The 18-year freedom from hypertension was $88 \%(95 \% \mathrm{CI}, 72 \%-95 \%)$.

\section{DISCUSSION}

Currently, the best surgical technique to repair interrupted aortic arch remains disputed. ${ }^{1}$ Most favor a direct anastomosis between the interrupted segments of aorta. ${ }^{2-5}$ The benefits of the addition of a patch to the repair remain controversial. ${ }^{6-}$

${ }^{8}$ Some have also recommended the use of a flap made from the stump of a carotid or subclavian vessel. ${ }^{9}$ Although most centers currently favor single-stage repair of associated cardiac lesions, some still advocate 2-stage repairs under all or selected circumstances. ${ }^{3,5,7,9-11}$ Each center has usually favored only one of these multiple surgical approaches on the basis of the personal preferences and past experiences

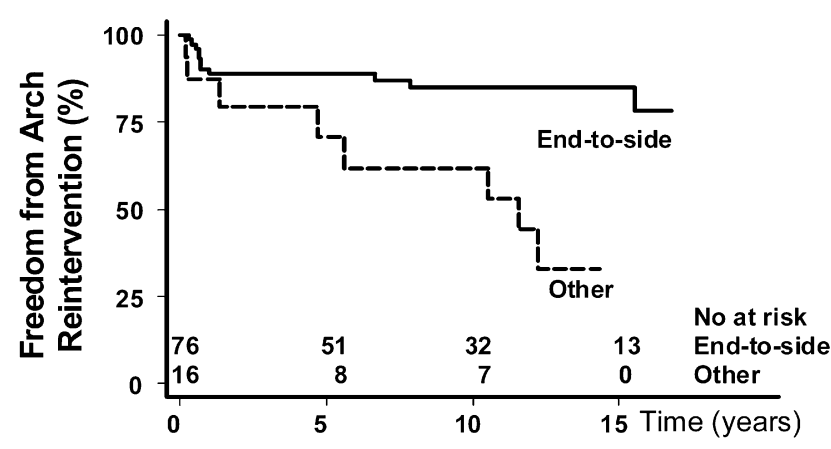

FIGURE 3. Kaplan-Meier graph of freedom from arch reintervention for 92 of 101 hospital survivors of repair (9 patients unavailable for follow-up). 


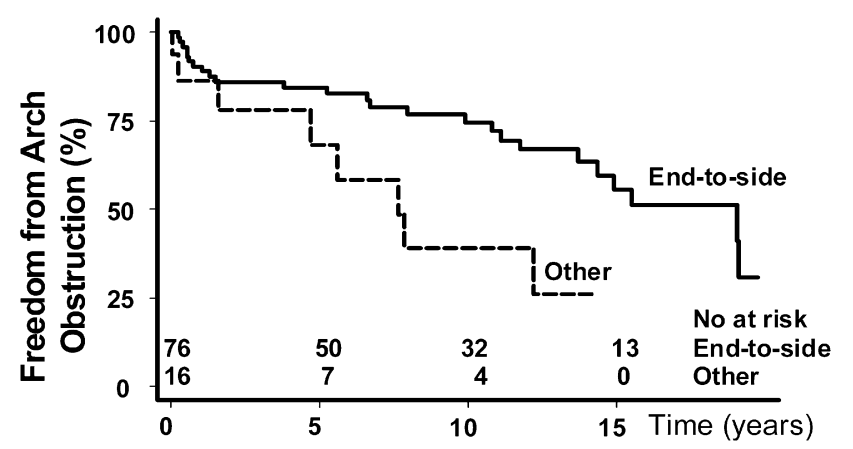

FIGURE 4. Kaplan-Meier graph of freedom from arch obstruction for 92 of 101 hospital survivors of repair (9 patients unavailable for follow-up).

of its surgeons. Because patients with this rare condition can never be evenly distributed among different surgical approaches and because in multicentric studies noticeable differences have been noted among outcomes at different centers, it will remain difficult to prove the superiority of any given approach through the analysis of early outcomes. ${ }^{6}$ Currently, there are only scarce reports on outcomes of interrupted aortic repairs beyond the first decade after surgery. At a time when most surgeons achieve similar early survivals for these patients, the best demarcation of the superiority of a technique of arch repair might arguably be better late outcomes. ${ }^{4,5,11}$ Recurrent obstruction at the level of the repair has been demonstrated. Also, although there are increasing concerns regarding late occurrence of systemic hypertension in patients who have undergone conventional repair of coarctation, nothing is yet known regarding the incidence of hypertension among patients undergoing repair of interrupted aortic arch. ${ }^{12-14}$

The repair of interrupted aortic arch by direct anastomosis without interposition of graft material has remained our favorite approach since $1985 .{ }^{15}$ We believe that the longterm outcomes of our patients may serve as a benchmark for the expectations for those operated on with this particular technique.

\section{Limitations}

This is a retrospective review of our experience during a long period. The results presented here may not accurately reflect today's achievements. Single-stage repair with an end-to-side anastomosis performed through a sternotomy was obviously favored among our patients. This series therefore determines what can be achieved with this approach but is limited in its analysis of the comparative benefits of the different surgical techniques used. The other techniques were used early in our experience, when patient management may have been less than optimal. Use of another technique may also have reflected the technical difficulties encountered or the complexity of the associated cardiac lesions. These procedures were performed during an extended period, and the results observed may reflect this fact. In particular, because cardiac arrest and selective cerebral perfusion were used in different periods, this study cannot provide an adequate comparison of these approaches. Finally, the determination of the late incidence of systemic hypertension depends on the criteria used to define hypertension. Because of the design of the study, we had no access to the height or the body surface area of the patients at last examination, and we therefore we could not use normative data. It is possible that 24 -hour blood pressure monitoring and exercise testing of the patients would have detected more hypertension among these patients than we did. In addition, the results of late hypertension and arch obstruction reported here were extracted from letters of referring cardiologists, and it is unclear whether in some cases the existence of lesions of the origin of the subclavian vessels may have masked the real incidence of these complications.

\section{Early Outcomes}

Our in-hospital mortality of $10 \%$ is among the lowest reported for this group of patients. ${ }^{2,9}$ The technique of end-toside repair was feasible without any patch interposition in most instances. A key aspect of the technique is the extensive dissection of the descending aorta. To avoid left main bronchus compression, sufficient space should be left under the arch concavity, and care should be taken to avoid performing the implantation of the descending aorta too low on the ascending aorta. Left main bronchus compression is a known complication of the technique. ${ }^{5,11}$ In 3 of the 6 occurrences of this complication, the patient had truncus arteriosus. Today, whenever the space left under the arch may become too narrow, we tend to perform the anastomosis more distally on the arch and at times, if deemed necessary, complete the repair with the addition of a patch to alleviate the risk of bronchial compression. Patch augmentation has already been shown to improve survival after aortic arch repair. ${ }^{6,7}$ It was performed so infrequently in this series, however, that its beneficial impact cannot be evaluated. In recent years, we have also more frequently performed aortic arch patch augmentation in patients with a functionally single ventricle requiring a concomitant Damus and shunting procedures, because the size of the Damus repair may further limit the space under the concavity of the arch.

Single-stage repair has been our favorite approach since the beginning of our experience. Although in this study its benefits could not be specifically compared with those of a 2-stage approach, we believe that this practice also contributed to our low in-hospital mortality.

Subaortic LVOT obstruction is an intrinsic component of interrupted aortic arch disease. Its diagnosis is difficult to establish with certainty before completion of the repair. It has been associated with higher mortality. ${ }^{4,10}$ As published previously, LVOT obstruction had no noticeable impact on the early outcomes of our patients. ${ }^{16}$ Interestingly, repair of associated anomalies did not appear to be a risk factor for 
mortality. The only identified risk factor for mortality was lack of VSD closure at the time of repair, which we believe selected the less severe cases with shunting restricted to a single VSD.

\section{Late Outcomes}

The most striking finding of this study is the high incidence of recurrent arch obstruction and arch reintervention. Eighteen years after arch repair, half of the patients had recurrent obstruction of the aortic arch, and a quarter needed arch reintervention. This high rate of obstruction is in contrast with the low rate of hypertension at last follow-up. Although this risk is important to convey to patients' families, it seems difficult to determine the best way to improve these results. There was a slight trend toward improvement between operative eras, but it seems unlikely that we are now performing better operations than in the past. Patients operated on by sternotomy with an end-to-side repair had fewer reinterventions and recurrent obstructions than those operated with other techniques. We should nonetheless not deduce from this finding that more extensive use of this technique will prevent recurrent obstruction, because the patients were obviously not equally distributed between groups. Under exceptional circumstances, it may seem reasonable to add a patch to the repair whenever undue tension is suspected. We would not recommend the addition of a patch in all cases, because this would significantly increase the length of the procedure and because the large proportion of the patients surviving to adulthood without any obstruction should have a long-lasting result thereafter. The finding that patients who had an aberrant subclavian artery had more risk of recurrent obstruction may indicate how to perform the repair better. The high incidence of aberrant subclavian artery in patients with interrupted aortic arches had already been noticed. ${ }^{17}$ In this instance, some have reported difficulties in performing a direct anastomosis. ${ }^{8,18}$ We believe that a larger amount of ductal tissue is present in the presence of an aberrant subclavian artery. Unless the artery is sacrificed, which has not been our usual practice, there is an increased risk of leaving remnants of ductal tissue in the area of the anastomosis, contributing to the subsequent narrowing of the area. This finding encourages us to perform drastic resection of all ductal tissue before the completion of the repair. We believe that proximal ligation of the right subclavian artery, with or without its reimplantation, may be considered when its anomalous implantation seems to compromise the repair. Patients who required reoperation for LVOT obstruction had higher risk of late arch obstruction and arch reintervention. This is probably because restriction of the LVOT correlates with more significant disease of all left-sided structures, including the aorta. Only a limited number of patients with LVOT obstruction required reintervention, so no technical changes should be offered for this subset of patients.

\section{CONCLUSIONS}

In conclusion, we believe single-stage repair with end-toside anastomosis to be the optimal approach for most neonates born with interrupted aortic arch. This repair provided long-lasting relief of arch obstruction with low early mortality. After 2 decades of experience with this approach, the incidence of late hypertension seems minimal. The need for further arch reintervention warrants close follow-up of these patients.

\section{References}

1. Mishra PK. Management strategies for interrupted aortic arch with associated anomalies. Eur J Cardiothorac Surg. 2009;35:569-76.

2. Morales DL, Scully PT, Braud BE, Booth JH, Graves DE, Heinle JS, et al. Interrupted aortic arch repair: aortic arch advancement without a patch minimizes arch reinterventions. Ann Thorac Surg. 2006;82:1577-84.

3. Oosterhof T, Azakie A, Freedom RM, Williams WG, McCrindle BW. Associated factors and trends in outcomes of interrupted aortic arch. Ann Thorac Surg. 2004; 78:1696-702.

4. Sell JE, Jonas RA, Mayer JE, Blackstone EH, Kirklin JW, Castaneda AR. The results of a surgical program for interrupted aortic arch. J Thorac Cardiovasc Surg. 1988;96:864-77

5. Serraf A, Lacour-Gayet F, Robotin M, Bruniaux J, Sousa-Uva M, Roussin R, et al. Repair of interrupted aortic arch: a ten-year experience. J Thorac Cardiovasc Surg. 1996;112:1150-60.

6. McCrindle BW, Tchervenkov CI, Konstantinov IE, Williams WG, Neirotti RA, Jacobs ML, et al. Risk factors associated with mortality and interventions in 472 neonates with interrupted aortic arch: a Congenital Heart Surgeons Society study. J Thorac Cardiovasc Surg. 2005;129:343-50.

7. Tchervenkov CI, Tahta SA, Jutras L, Beland MJ. Single-stage repair of aortic arch obstruction and associated intracardiac defects with pulmonary homograft patch aortoplasty. J Thorac Cardiovasc Surg. 1998;116:897-904.

8. Tlaskal T, Hucin B, Kucera V, Vojtovic P, Gebauer R, Chaloupecky V, et al. Repair of persistent truncus arteriosus with interrupted aortic arch. Eur J Cardiothorac Surg. 2005;28:736-41

9. Brown JW, Ruzmetov M, Okada Y, Vijay P, Rodefeld MD, Turrentine MW. Outcomes in patients with interrupted aortic arch and associated anomalies: a 20-year experience. Eur J Cardiothorac Surg. 2006;29:666-74.

10. Luciani GB, Ackerman RJ, Chang AC, Wells WJ, Starnes VA. One-stage repair of interrupted aortic arch, ventricular septal defect, and subaortic obstruction in the neonate: a novel approach. $J$ Thorac Cardiovasc Surg. 1996;111:348-58.

11. Tlaskal T, Hucin B, Hruda J, Marek J, Chaloupecky V, Kostelka M, et al. Results of primary and two-stage repair of interrupted aortic arch. Eur J Cardiothorac Surg. 1998;14:235-42.

12. Hager A, Kanz S, Kaemmerer H, Schreiber C, Hess J. Coarctation Long-term Assessment (COALA): significance of arterial hypertension in a cohort of 404 patients up to 27 years after surgical repair of isolated coarctation of the aorta, even in the absence of restenosis and prosthetic material. J Thorac Cardiovasc Surg. 2007;134:738-45.

13. Ou P, Celermajer DS, Mousseaux E, Giron A, Aggoun Y, Szezepanski I, et al. Vascular remodeling after "successful" repair of coarctation: impact of aortic arch geometry. J Am Coll Cardiol. 2007;49:883-90.

14. Ou P, Celermajer DS, Raisky O, Jolivet O, Buyens F, Herment A, et al. Angular (Gothic) aortic arch leads to enhanced systolic wave reflection, central aortic stiffness, and increased left ventricular mass late after aortic coarctation repair: evaluation with magnetic resonance flow mapping. J Thorac Cardiovasc Surg. 2008;135:62-8.

15. Karl TR, Sano S, Brawn W, Mee RB. Repair of hypoplastic or interrupted aortic arch via sternotomy. J Thorac Cardiovasc Surg. 1992;104:688-95.

16. Fulton JO, Mas C, Brizard CP, Cochrane AD, Karl TR. Does left ventricular outflow tract obstruction influence outcome of interrupted aortic arch repair? Ann Thorac Surg. 1999;67:177-81.

17. Ramaswamy P, Lytrivi ID, Thanjan MT, Nguyen T, Srivastava S, Sharma S, et al Frequency of aberrant subclavian artery, arch laterality, and associated intracardiac anomalies detected by echocardiography. Am J Cardiol. 2008;101:677-82.

18. Vouhe PR, Mace L, Vernant F, Jayais P, Pouard P, Mauriat P, et al. Primary definitive repair of interrupted aortic arch with ventricular septal defect. Eur J Cardiothorac Surg. 1990;4:365-70. 


\section{Discussion}

Dr Frank L. Hanley (Stanford, Calif). This is a nice study. Mohan Reddy sends his regards and also apologizes for not being here; he was unable to leave because of coverage issues at home.

As you mentioned, there are many, many ways to skin this cat. It just so happens that we skin it exactly the same way you do. We also do a midline sternotomy with intracardiac repair and end-toside arch anastomosis. And I don't think you emphasized it here, but you also have used antegrade cerebral perfusion since 2000 . We also have used antegrade cerebral perfusion exclusively since 1992. So we have the exact same approach that you do.

Long-term follow-up of interrupted aortic arch repair is not well documented in the literature, so your study is clearly an important addition. And with a consistent approach for more than 20 years, your late information on recurrence rates and hypertension, acknowledging the interpretation issues that you yourself mention, are informative data. Also, just as an aside, it's nice to have a subject that we agree on.

You included all your patients with interrupted aortic arch, including those with single ventricles, and all types of VSDs. But what you didn't do in the analysis, and all the information was there for you to pull out, is isolate as a separate subanalysis the "typical" type A or B interrupted arch with posterior malaligned conoventricular VSD. I believe that 59 patients in your total series fall into this category. Analysis of this somewhat homogeneous subgroup would allow some comparison with other studies reporting on this "typical" interrupted arch group. Did you do any of that kind of analysis?

Dr d'Udekem. Actually, we did not do a separate analysis of the patients with malaligned VSDs in the frame of this long-term follow-up study. What we did do is precisely take this group of patients and perform much more detailed analysis.

Dr Hanley. So playing that same idea out a little bit further, how do you manage the problematic LOVT in double-ventricle patients with interrupted aortic arch? I noticed that you had 6 patients who underwent some resection of the subaortic area at the initial operation, but you also did a half dozen or so Damus procedures. Specifically, were any of those Damus procedures done as an alternative to direct LVOT resection in those patients with isolated VSD and difficult subaortic areas?

Dr d'Udekem. As far as I remember, all of the Damus procedures were performed in cases of single-ventricle pathology.
Dr Hanley. If you have a really difficult subaortic area that you don't want to address, a Damus procedure and a conduit provide a way out. We have done that occasionally, but very, very rarely. So when you would resect and when would you do a Damus procedure?

Dr d'Udekem. I'm sure that it's an option that we would consider in very difficult subaortic stenosis, but it's not an option that we've done often. In this particular study, I cannot remember that a Damus procedure was done for subaortic obstruction, but it's definitely an option we would still consider today.

Dr Hanley. Do you have objective criteria for when you address the LVOT? Because, of course, the preoperative physiology is nonpredictive. Do you have an anatomic criterion or set of criteria that you use?

Dr d'Udekem. The way we do it is very much like our predecessors. We go in and we have a look. And sometimes we do nothing, or resect, or take another step on the basis of the intraoperative findings.

Dr Hanley. Final question. Your incidence of late reoperation is roughly half your incidence of late identification of some arch obstruction. What criteria do you use for intervention versus observation when you have identified late obstruction?

Dr d'Udekem. We have, to be honest, no strict criteria. We decide on a case-by-case basis. Clearly, however, if we have a gradient above 20 to $25 \mathrm{~mm} \mathrm{Hg}$, we would recommend balloon dilatation or even surgical intervention. I think the evidence is accumulating that if you don't have the right arch geometry, even with low gradients, you should do something to this arch, not hesitating to reoperate. And I think in the past few years our threshold for reoperation on an abnormal arch has gotten lower.

Dr Joseph J. Amato (Chicago, Ill). This was an excellent study that you presented. From your diagram and from your first comment, you stated that you did extensive resection. I assume that you divided some of the intercostal arteries as the aorta was pulled upward. How many intercostals were divided? If you did dissect any of them, how many? Did you have any incidence of paralysis or at least paresis?

Dr d'Udekem. When I was in Melbourne, I got the clear message that for all this type of work I had to dissect the first 3 pairs of intercostal arteries. Dissect, cauterize, and divide the first 3 pairs of intercostal arteries, and I have religiously done so every time since. We do that for Norwood procedures as well. I've never seen and never heard about either paraplegia or paresis in that setting.

Dr Amato. Excellent. Thank you very much. 
APPENDIX 1. Collected variables

\begin{tabular}{ll}
\hline Time frame & \\
\hline Preoperative & Sex \\
& Age at operation \\
& Type of interruption \\
& Associated cardiac condition \\
& Bicuspid valve \\
& Aberrant right subclavian artery \\
& Subaortic stenosis \\
& Univentricular heart \\
& 22q11 deletion \\
& Prostaglandin infusion \\
& Mechanical ventilator \\
& Inotropic support \\
& Renal failure \\
& Necrotizing enterocolitis \\
Era (1985-1995 vs 1996-2007) & End-to-side/other repair \\
Associated procedures \\
Graft interposition \\
Left ventricular outflow tract obstruction relief \\
Thoracotomy/sternotomy \\
1-stage/2-stage repair \\
Bronchus compression \\
Cardiopulmonary bypass time \\
Cardiac arrest time \\
Selective cerebral perfusion \\
Bronchus compression \\
Arch obstruction \\
Arch reoperation \\
Balloon dilatation \\
Other cardiac reoperations \\
\hline
\end{tabular}

APPENDIX 2. Risks factors for late outcomes among hospital survivors

\begin{tabular}{lcc}
\hline & \multicolumn{2}{c}{$\boldsymbol{P}$ value } \\
\cline { 2 - 3 } & Univariate & Multivariate \\
\hline Late mortality & & \\
Double-outlet right ventricle & .013 & \\
Pulmonary arterial banding & .017 & \\
Thoracotomy & .025 & \\
2-Stage repair & .025 & \\
Bronchus compression & .006 & \\
Other than end-to-side & .009 & \\
Arch reintervention & & \\
Thoracotomy & .002 & \\
Other than end-to-side & .003 & \\
Interposition conduit & $<.001$ & \\
Further LVOTO relief & .006 & \\
Arch obstruction & & \\
Aberrant right subclavian artery & .036 & \\
Era 1985-1995 & .048 & \\
Thoracotomy & .01 & \\
Other than end-to-side & .02 & \\
Interposition conduit & .006 & \\
Further LVOTO relief & .005 & \\
\hline LVOTO, Left ventricular outflow tract obstruction. & & \\
\end{tabular}

